\title{
Accuracy of self-reported intake of signature foods in a school meal intervention study: comparison between control and intervention period
}

\author{
Anja Biltoft-Jensen ${ }^{1 *}$, Camilla Trab Damsgaard ${ }^{2}$, Rikke Andersen ${ }^{1}$, Karin Hess Ygil $^{1}$, \\ Elisabeth Wreford Andersen ${ }^{3}$, Majken Ege ${ }^{1}$, Tue Christensen ${ }^{1}$, Louise Bergmann Sørensen ${ }^{2}$, \\ Ken D. Stark ${ }^{4}$, Inge Tetens ${ }^{1}$ and Anne-Vibeke Thorsen ${ }^{1}$ \\ ${ }^{1}$ Division of Nutrition, The National Food Institute, Technical University of Denmark, Mørkhøj Bygade 19, \\ 2860 Søborg, Denmark \\ ${ }^{2}$ Department of Nutrition, Exercise and Sports, Faculty of Science, University of Copenhagen, Nørre Allé 51 , \\ 2200 Copenhagen N, Denmark \\ ${ }^{3}$ Department of Applied Mathematics and Computer Science, Technical University of Denmark, \\ Richard Petersens Plads, Building 324, 2800 Kongens Lyngby, Denmark \\ ${ }^{4}$ Department of Kinesiology, University of Waterloo, 200 University Avenue West, Waterloo, ON, Canada N2L $3 G 1$ \\ (Submitted 20 November 2014 - Final revision received 22 April 2015 - Accepted 13 May 2015 - First published online 20 July 2015)
}

\section{Abstract}

Bias in self-reported dietary intake is important when evaluating the effect of dietary interventions, particularly for intervention foods. However, few have investigated this in children, and none have investigated the reporting accuracy of fish intake in children using biomarkers. In a Danish school meal study, 8- to 11-year-old children ( $n$ 834) were served the New Nordic Diet (NND) for lunch. The present study examined the accuracy of self-reported intake of signature foods (berries, cabbage, root vegetables, legumes, herbs, potatoes, wild plants, mushrooms, nuts and fish) characterising the NND. Children, assisted by parents, self-reported their diet in a Web-based Dietary Assessment Software for Children during the intervention and control (packed lunch) periods. The reported fish intake by children was compared with their ranking according to fasting whole-blood EPA and DHA concentration and weight percentage using the Spearman correlations and cross-classification. Direct observation of school lunch intake ( $n$ 193) was used to score the accuracy of food-reporting as matches, intrusions, omissions and faults. The reporting of all lunch foods had higher percentage of matches compared with the reporting of signature foods in both periods, and the accuracy was higher during the control period compared with the intervention period. Both Spearman's rank correlations and linear mixed models demonstrated positive associations between $\mathrm{EPA}+\mathrm{DHA}$ and reported fish intake. The direct observations showed that both reported and real intake of signature foods did increase during the intervention period. In conclusion, the self-reported data represented a true increase in the intake of signature foods and can be used to examine dietary intervention effects.

Key words: Web-based food diaries: $\boldsymbol{n}$-3 Fatty acids: Direct observation: Matches: Intrusions: Omissions: Faults

Dietary intervention trials aimed at changing dietary intake of individuals, and self-reported dietary data are often used to assess the efficacy of dietary interventions. Because of the participant burden and the complex relationships humans have with their diet, all recording of diet is subject to bias. Examples of biases are social desirability, memory faults related to foods and components of foods (e.g. condiments in sandwiches), and difficulties determining accurate portion size ${ }^{(1,2)}$. These measurement issues are more problematic regarding children given the added variability in cognitive development and possible limited food experience and vocabulary ${ }^{(3)}$.
The OPUS centre (optimal well-being, development and health for Danish children through a healthy New Nordic Diet) carried out a cluster-randomised school meal trial with 834 Danish children, 8-11 years of age, with the aim to test the effect of serving school meals based on the New Nordic Diet (NND) on dietary intake, cognitive performance and health-associated outcomes ${ }^{(4)}$. In the OPUS School Meal Study, children were served school lunches and snacks based on the NND. The overall guidelines and dietary composition and nutrient content of the NND were described in detail by Mithril et al. ${ }^{(5,6)}$. Apart from being palatable,

Abbreviations: NND, New Nordic Diet; WebDASC, Web-based Dietary Assessment Software for Children.

* Corresponding author: A. Biltoft-Jensen, fax +45 358871 19, email apbj@food.dtu.dk 
environmentally friendly and from the Nordic region, the NND meals were designed to contain more berries, cabbage, root vegetables, legumes, fresh herbs, potatoes, wild plants and mushrooms, whole grains, nuts, fish and seaweed than the average Danish $\operatorname{diet}^{(7)}$. These foods, characterising the NND, were called the signature foods of the NND. To measure dietary intake during the school meal study, a self-administered and intuitive Web-based Dietary Assessment Software for Children (WebDASC) was developed ${ }^{(8)}$. WebDASC was validated for energy as well as fruit and vegetable reporting against energy expenditure and plasma carotenoid concentrations, respectively ${ }^{(9,10)}$. However, it has never been investigated how well small intakes of rarely eaten but highly health-potent foods, such as the specific signature foods of the NND, are self-reported and whether reporting accuracy varies between control and intervention conditions. The intervention itself could cause participants to over-report their compliance with the NND and overestimate the amounts of signature foods eaten, or it could be more difficult for participants to report the unfamiliar NND foods such as legumes and different types of cabbage. Such intervention-associated reporting errors could complicate the interpretation of the results.

Objective methods such as direct observation and biomarkers are available for validating and evaluating dietary reporting. Direct observation involves comparison of foods reported eaten to foods actually eaten by observing what participants really eat. Direct observation of meal consumption is considered the 'gold standard' to evaluate the validity of dietary assessment tools, because eating is an observable behaviour and can provide unbiased information about a subject's actual intake $^{(11,12)}$. Results from methodological studies validating children's dietary recalls using direct observation have shown that accuracy was better for previous 24-h recalls than previous -day recalls, that children recalled school lunch intake more accurately than school breakfast, and that observation of school meals did not affect children's recalls ${ }^{(13)}$. Previously reported results from the OPUS School Meal Study have shown that the NND was successful in increasing the children's intake of fish ${ }^{(14)}$. In line with this, the school meal intervention also increased $n$ - 3 long-chain PUFA status measured as the sum of EPA $(20: 5 n-3)$ and DHA $(22: 6 n-3)$ on a weight percentage basis (w/w\%) in fasting whole blood (LB Sørensen, CT Damsgaard, SM Dalskov, RA Petersen, N Egelund, CB Dyssegaard, KD Stark, A Andersen, I Tetens, A Astrup, KF Michaelsen and L Lauritzen, unpublished results). EPA and DHA can be used as an objective indicator of fish intake because their endogenous synthesis from their precursor $\alpha$-linolenic acid $(18: 3 n-3)$ is low, and fish and seafood are the main dietary sources ${ }^{(15)}$ Whole blood is a mixture of plasma and erythrocytes, and EPA and DHA content in these blood components have previously been used as biomarkers for fish intake ${ }^{(15-17)}$. EPA and DHA expressed on a w/w\% bases have also been used as biomarker for EPA and/or DHA intake ${ }^{(15,18-20)}$. Expressed on $\mathrm{a} \mathrm{w} / \mathrm{w} \%$ basis, the individual fatty acid is determined as the percentage it contributes to all plasma fatty acids; hence, the percentage of each individual fatty acid is influenced by changes in intake of other fatty acids ${ }^{(21)}$. When fatty acid results are expressed as concentrations $(\mu \mathrm{g} / 100 \mu \mathrm{l})$, changes in fatty acids are independent of each other; however, they are not adjusted in relation to the total level of fatty acids in plasma; hence, a high content of an individual fatty acid can be due to a high total fatty acid level. This makes it relevant to express EPA and DHA in both ways.

Only a few validation studies using biomarkers as a reference method have been carried out with children ${ }^{(10,22,23)}$, and to our knowledge, none have validated reported fish intake using biomarkers.

Biomarkers, in general, convey no information about what is eaten at which meal on which day. Combining the biomarker validation with direct observations gives insight into the reporting accuracy of reported school meal intake in relation to the reporting accuracy of the signature foods in the NND.

The aim of the present study was to examine the reporting accuracy obtained when 8- to 11-year-old children, assisted by parents, self-report the NND signature foods in school meals during control and intervention periods. Direct observation of intake was used to score the accuracy of food-reporting and fasting whole-blood EPA and DHA in $\mu \mathrm{g} / 100 \mu \mathrm{l}$, and w/w\% was used to rank respondents according to their reported fish intake.

\section{Methods}

\section{Study design and recruitment}

The OPUS School Meal Study was a cluster-randomised, controlled unblinded cross-over study. In two 3-month periods during the 2011-12 school year, 834 children from third and fourth grade in nine municipal schools received school meals based on the NND and their usual packed lunch (control) for 3 months in random order. The study design and recruitment to the OPUS School Meal Study have previously been described in detail ${ }^{(4)}$.

The NND menus were produced locally at each school by trained personnel hired for the study. During the 3-month NND intervention period, the children were offered a midmorning snack, an ad libitum hot lunch meal and an afternoon snack complying with the principles of the $\mathrm{NND}^{(5-7)}$. The NND lunch menu was served buffet style during the five weekly schooldays, and in a weekly repertoire consisting of a soup day, a meat day, a vegetarian day, a fish day and a buffet day with premade leftovers. The children were encouraged to taste everything and to keep a reasonable plate distribution with vegetables and starchy foods filling the majority of the plate. The meals were free of charge for all the children in the invited school classes. During the 3-month control period, the children brought their usual packed lunches from home typically consisting of open Danish rye bread sandwiches with various toppings, such as sliced meat products, chocolate spread and liver paste, and fruit and/or vegetables ${ }^{(24)}$. The present study was conducted according to the guidelines laid down in the Declaration of Helsinki, and all procedures involving human subjects were approved by the Regional Research Ethics Committee (H-1-2010-124), and the trial was registered in the database www.clinicaltrials.gov (no. NCT 01457794). Written informed consent was obtained from custody holders of all participating children. 


\section{Background information}

At baseline, at least one parent or custody holder together with each child underwent a 2 -h in-depth interview either at the school or at home by a trained interviewer including verbal, hands-on and written instructions using the dietary assessment tool. The interview garnered background information such as sex, age and socio-economic status of the household. The educational level of the household was categorised according to the standard classifications of Statistics Denmark.

\section{Food-reporting in the Web-based Dietary Assessment Software for Children}

Children, assisted by parents, recorded their diet in WebDASC in the evening after the final eating occasion on each day for seven consecutive days. WebDASC guided respondents through six daily eating occasions (breakfast, morning snack, lunch, afternoon snack, dinner and evening snack). For the diet recording, a database of 1300 food items was available, either through category browsing or free text search, assisted by a spell-check application. The daily NND lunch menus could be searched using the category browsing; by browsing OPUS season, then daily menu, and then all lunch items for a particular day were displayed in the food items list for reporting. It was also possible to type in foods not otherwise found through category browsing or text search. The amount consumed was estimated by selecting the portion size from four different digital images among 320 photo series. Furthermore, participants recorded intake of dietary supplements on a daily basis and whether a recording day represented usual or unusual intake. WebDASC included internal checks for frequently forgotten foods (spreads, sugar, sauces, dressings, snacks, candy and beverages). WebDASC used an animated armadillo as a guide and a food-meter and game to create motivation. For participants to be included in the analyses, the WebDASC had to be completed for at least three weekdays and one weekend day. The intake of foods and nutrients was calculated for each individual using the software system GIES (version 1.000 d 26 February 2010) developed at the National Food Institute, Technical University of Denmark, and the Danish Food Composition Databank (version 7; Søborg, Denmark; 2 March 2009). Fish was classified as lean fish ( $<4 \mathrm{~g}$ fat/100 g; e.g. cod, shrimp and flounder) or fatty fish ( $\geq 4 \mathrm{~g}$ fat/100 g; e.g. salmon, herring and mackerel). Based on reported energy intake and estimated $\mathrm{BMR}^{(25)}$, children were categorised as under-reporters if energy intake BMR $\leq 1 \cdot 05^{(26)}$. Children were categorised as fish oil supplement user if they took $n$ - 3 long-chain PUFA containing supplements $\geq 1$ time/week.

\section{Observing food intake at lunch by photography and weighing}

Two of the nine selected schools were randomly assigned to participate in the direct observation ( $n$ 193), which took place on the exact same five schooldays as they reported their diet in the WebDASC. The packed lunches were usually eaten in the class rooms during the control period. Solid polystyrene plates and trays tagged with class, date and ID numbers were distributed to all children in the classrooms before lunch break. The children were asked to unpack their packed lunches from home, place their food on the plate and to separate items and open up the sandwiches so all food items would be observable. The children brought their food to the weighing station outside the classroom where a trained assistant weighed the plate (Soehnle; Vera 67002 , with a precision of $\pm 1 \mathrm{~g}$ ) and then to the photo station where another trained assistant took a photo of the plate (Nikon COOLPIX S 210 digital camera). When the children had finished eating, the procedure was repeated. Any package or wrapping that was weighed the first time (yoghurt and noodle cups, muesli bar wrappings, etc.) were left on the plate and also weighed the second time. The specific weight of the plate was subtracted from the preand post-measures.

The same procedure was used for the NND meals except that the food was eaten in, and the measurements taken, in a common eating room. If the children had a second serving, the procedure was repeated and the plate was weighted and photographed before and after eating.

One experienced dietitian assessed the accuracy of the diet records of children at lunch for each individual by scoring the items reported against the two images (before and after eating). Each item was classified either as a match (items recorded eaten and observed eaten), an intrusion (items reported eaten but not observed eaten), an omission (items observed eaten but not reported eaten) or a fault (items reported eaten does not describe the items observed eaten). Matches, omissions and intrusions also included the assessment of the recorded serving size, e.g. reporting half an apple instead of one apple observed (judged by WebDASC image weight), would be omitting half a fruit, and reporting two apples instead of one observed (judged by WebDASC image weight), would be intruding one fruit. The signature foods of the NND included in the reporting accuracy scoring were berries, nuts, cabbage, root vegetables, potatoes, legumes, fresh herbs, wild plants and mushrooms, and fish.

For a food to be indicated as eaten, it should be reasonably close to the smallest portion size image in the WebDASC. This portion size differed from signature food to signature food and was small for herbs $(1 \mathrm{~g})$ and larger for other signature foods such as root vegetables (15 g).

\section{Weight, height, blood samples and determination of fasting whole-blood n-3 fatty acids}

Overnight fasting blood samples and weight and height measurements were collected in a mobile laboratory placed outside the school during the week after the dietary reporting. Participants were weighed, without shoes and in light indoor clothing, to the nearest $0.1 \mathrm{~kg}$ on an electronic digital scale (Tanita BWB-800S). Their height was measured without shoes to the nearest $0 \cdot 1 \mathrm{~cm}$ with a stadiometer (CMS Weighing Equipment Limited). The prevalence of underweight, overweight and obesity was based on age- and sex-specific 
cut-offs defined by centiles passing through a BMI of 18.5, 25 and $30 \mathrm{~kg} / \mathrm{m}^{2}$ at 18 years, respectively ${ }^{(27)}$.

Local anaesthetic patches (EMLA; Astra Zeneca) were sent to the families with an instruction before the clinical measurements. A fasting venous blood sample was drawn from the antecubital vein. Heparinised blood was mixed with $0 \cdot 1 \%$ butylated hydroxytoluene (Sigma-Aldrich) in ethanol $(0 \cdot 1 \mathrm{ml} /$ $\mathrm{ml}$ blood) and stored at $-80^{\circ} \mathrm{C}$. Whole-blood fatty acid composition was measured by a high-throughput gas chromatographic method as described in detail previously ${ }^{(28,29)}$. Briefly, fatty acid methyl esters were prepared from wholeblood lipids through direct transesterification using $14 \% \mathrm{BF}_{3}$ in methanol with convectional heat $\left(95^{\circ} \mathrm{C}\right.$ for $\left.1 \mathrm{~h}\right)$. Fatty acid methyl esters were analysed by GC with flame ionisation detection using a Varian 3900 equipped with a DB-FFAP $15 \mathrm{~m} \times 0.10 \mathrm{~mm}$ inner diameter $\times 0.10 \mu \mathrm{m}$ film thickness column. Fatty acids were identified by comparison to an external mixed standard (GLC-462; Nu-Chek Prep), and absolute concentrations of individual fatty acids ( $\mu \mathrm{g}$ of fatty acid/ $100 \mu \mathrm{l}$ of whole blood) were determined by comparison with an internal standard added before transesterification (22:3n-3 ethyl ester; Nu-Chek Prep). EPA and DHA were expressed as absolute concentrations $(\mu \mathrm{g} / \mu \mathrm{l})$ and composition by weight percentage $(\mathrm{w} / \mathrm{w} \%)$. The inter- and intraassay CV were 4.5 and $1.2 \%$ (EPA) and 6.4 and $2.4 \%$ (DHA). The limit of quantification for the fatty acids ranged between 0.007 and $0.01 \mu \mathrm{g} / 100 \mu \mathrm{l}$ as determined by calibration curves.

\section{Statistical analyses}

$\chi^{2}$ Tests were used to test the differences in reporting accuracy between control and intervention periods and also to test the differences between the number of children with reported zero intakes and positive intakes of signature foods at lunch time in the control and intervention periods.

Reported fish intake was compared with the whole-blood EPA and DHA $(\mu \mathrm{g} / \mu \mathrm{l}$ and $\mathrm{w} / \mathrm{w} \%)$. This was first done using Spearman's correlations separately for intervention and control periods where both unadjusted correlations and adjusted correlations (adjusting for sex, grade, household education, BMI and fish oil supplement) were calculated. Then, total fish intake was grouped into quartiles (separately for intervention and control periods) and similarly whole blood $\mathrm{EPA}+$ DHA $(\mu \mathrm{g} / \mu \mathrm{l}$ and $\mathrm{w} / \mathrm{w} \%)$. The cross-tabulation is then presented for total fish intake and EPA + DHA in fasting whole blood to study the agreement. $\kappa$ statistics of agreement were calculated.

Whole-blood EPA + DHA $(\mu \mathrm{g} / \mu \mathrm{l}$ and $\mathrm{w} / \mathrm{w} \%)$ was used as an outcome in linear mixed models, to investigate the associations with reported fish intake. As the children were nested in classes, and the classes were nested in schools, the models included three random effects (child, class and school). The fixed effects included the following: sex; grade; dietary period (order of intervention and control periods); diet (packed lunch or NND); household education; BMI group; fish oil supplement use. There may be a different NND effect in relation to the order of periods and if children were served the NND meals during the first or second study period. The order of periods was added as an interaction to the model. The model fit was checked by residual plots and QQ plots, and if necessary, the outcome was transformed using $\log 2$.

All transformed variables were back-transformed using the anti-log when presenting the results. SAS version 9.3 was used for all statistical analyses. The significance level was chosen as $P<0 \cdot 05$.

\section{Results}

\section{Baseline characteristics}

Characteristics of all respondents ( $n$ 834) and the subsample participating in the direct observations ( $n$ 193) are presented in Table 1. Approximately, half of both the total sample and subsample were girls (48-54\%). The mean age was $10 \cdot 2$ (sD 0.6) years for both the total and the subsample. About half of the children in both samples were from households with a medium higher education or more. In the total sample and subsample, 13 and $12 \%$ were overweight or obese, respectively. Parental intentions to eat healthily were high among all participants as well as for the subsample (86 and $84 \%$, respectively).

\section{Dietary intake of all respondents}

The intake of macronutrients and foods are reported in detail by Andersen et $a l .{ }^{(14)}$. In short, the mean energy intake during the control and intervention periods was estimated to be $7 \cdot 5$ (SD 1.9) and 7.4 (SD 2.0) MJ/d, respectively. The mean reported energy intake to BMR ratio were 1.5 (SD 0.4 ) for both periods. The proportion of participants who under-reported energy intake was $11.4 \%$ in the control period and $15.5 \%$ in the intervention period. About $8 \%$ of the participants used dietary supplements containing fish oils in both periods. The total reported median intake of fish including both lean and fatty fish doubled in the intervention period $(9 \cdot 1 v \cdot 22 \cdot 1 \mathrm{~g} / \mathrm{d})$.

\section{Photographic and weighed observations of school lunch v. the recorded intakes of signature foods}

As illustrated in Table 2, signature foods made up $57 \%$ ( $n$ 1724) of the reported lunch foods during the intervention period. In contrast, only $11 \%$ ( $n$ 426) of the reported foods were signature foods in the control period. Likewise, the zero intake of cabbage, legumes, fresh herbs and berries was high (63-94\%) during the control period, but decreased significantly during the intervention period (28-42\%; Table 3 ). For total food-reporting at school lunch (including signature foods), a significantly $(P<0 \cdot 05)$ higher percentage matches and lower percentage faults were observed in the control period (matches 59\%; faults 3\%) than in the intervention period (matches 55\%; faults 6\%). The same picture was seen for the reporting of signature foods where $44 \%$ matches and $3 \%$ faults during the control period and 39\% matches and $9 \%$ faults during the intervention period were observed $(P<0.05)$. Most recording errors during control and 
Table 3. Number of children with reported zero intakes and positive intakes of signature foods at lunch time in the control period with packed lunches and intervention period when served a New Nordic Diet for lunch

\begin{tabular}{|c|c|c|c|c|c|c|c|c|c|}
\hline \multirow[b]{2}{*}{ Signature foods } & \multicolumn{4}{|c|}{ Control ( $n$ 166) } & \multicolumn{4}{|c|}{ Intervention ( $n$ 166) } & \multirow[b]{2}{*}{$P^{\star}$} \\
\hline & Zero intake & $\%$ & Positive intake & $\%$ & Zero intake & $\%$ & Positive intake & $\%$ & \\
\hline \multicolumn{10}{|l|}{ Lunch intake } \\
\hline Berries & 104 & 63 & 62 & 37 & 68 & 41 & 98 & 59 & $<0.001$ \\
\hline Nuts & 73 & 44 & 93 & 56 & 28 & 17 & 138 & 83 & $<0.001$ \\
\hline Cabbage & 156 & 94 & 10 & 6 & 69 & 42 & 97 & 58 & $<0.001$ \\
\hline Root vegetables & 62 & 37 & 104 & 63 & 6 & 4 & 160 & 96 & $<0.001$ \\
\hline Herbs & 111 & 67 & 55 & 33 & 34 & 20 & 132 & 80 & $<0.001$ \\
\hline Legumes & 126 & 76 & 40 & 24 & 47 & 28 & 119 & 72 & $<0.001$ \\
\hline Potatoes & 83 & 50 & 83 & 50 & 5 & 3 & 161 & 97 & $<0.001$ \\
\hline Fish & 82 & 49 & 84 & 51 & 22 & 13 & 144 & 87 & $<0.001$ \\
\hline
\end{tabular}

${ }^{*}$ Association between intervention and intake yes/no is studied using a simple $\chi^{2}$ test (or Fisher's exact test if the expected cell count is below 5).

not shown). The most difficult for the children to report during the intervention period were berries, wild plants and mushrooms, which had 29\% matches (results not shown).

The total amount of foods reported was higher than the total amount of food actually eaten at lunch both at control and intervention periods (control and intervention, mean reported: 214 (SD 134) and 237 (SD 182) g; weighed: 197 (SD 101) and 223 (SD 138) $g(P<0 \cdot 02)$ ). This supports that intrusions were the most common reporting error.

The direct observations showed that there was a true increase in reported consumption of signature foods during the intervention period since there were 323 instances of true reporting of signature foods during the control period compared with 1303 instances of true reporting during the intervention period (not taking portion size into account).

\section{Fasting whole-blood n-3 PUFA concentrations of all respondents}

The levels of EPA + DHA $(\mu \mathrm{g} / \mu \mathrm{l}$ and $\mathrm{w} / \mathrm{w} \%)$ were slightly higher in the intervention period compared with the control period $(8.0 \mu \mathrm{g} / 100 \mu \mathrm{l} v .7 .5 \mu \mathrm{g} / 100 \mu \mathrm{l} ; 3.6 v .3 .4 \%$; $P<0.0001$; Table 4). Unadjusted and partial Spearman's rank correlations between EPA + DHA in fasting whole blood and reported fish intake are presented in Table 5. Adjusted correlations showed that EPA + DHA were significantly correlated to total fish intake (control: 0.39 $(\mu \mathrm{g} / \mu \mathrm{l})$ and $0.38(\mathrm{w} / \mathrm{w} \%)$; intervention $0.30(\mu \mathrm{g} / \mu \mathrm{l})$ and $0.36(\mathrm{w} / \mathrm{w} \%), P<0.0001)$ and fatty fish intake (control: $0.40(\mu \mathrm{g} / \mu \mathrm{l})$ and $0.41(\mathrm{w} / \mathrm{w} \%)$; intervention $0.39(\mu \mathrm{g} / \mu \mathrm{l})$ and $0.35(\mathrm{w} / \mathrm{w} \%), P<0.0001)$ and less correlated to lean fish intake. Both unadjusted and partial correlations seemed slightly higher during the control period compared with the intervention period.

The cross-classification between reported fish intake and fasting whole-blood EPA + DHA content during both periods is shown in Fig. 1 as an exact and partial agreement. During control and intervention periods, $33-36 \%$ and $30-33 \%$ $(\mu \mathrm{g} / \mu \mathrm{l}-\mathrm{w} / \mathrm{w} \%)$ were classified in the correct quartile, $75-76 \%$ and $74-74 \%$ were classified in the correct or adjacent quartile, $19-18 \%$ and $20-21 \%$ were misclassified, and $6-7 \%$ were misclassified in the opposite quartile. Using $\mathrm{w} / \mathrm{w} \%$ gave almost identical results to $\mu \mathrm{g} / \mu \mathrm{l}$. The $\kappa$ statistic for the control period was $0 \cdot 11$ (95\% CI $0 \cdot 06,0 \cdot 15)$ using $\mu \mathrm{g} / \mu \mathrm{l}$ and $0 \cdot 15(95 \% \mathrm{CI} 0 \cdot 10,0 \cdot 20)$ using $\mathrm{w} / \mathrm{w} \%$. The agreement was not as good during the intervention period where the $\kappa$ statistic was 0.07 (95\% CI $0.03,0.12)$ using $\mu \mathrm{g} / \mu \mathrm{l}$ and $0 \cdot 11$ (95\% CI $0 \cdot 06,0 \cdot 16)$ using $\mathrm{w} / \mathrm{w} \%$.

Comparing the EPA + DHA $(\mu \mathrm{g} / \mu \mathrm{l})$ in fasting whole blood to fish intake using regression models showed a positive association between EPA + DHA and fish intake. When total

Table 4. Fasting whole-blood concentration and weight percentage of EPA and DHA in the control period with packed lunches and intervention period when served a New Nordic Diet for lunch

(Mean values and standard deviations; medians and interquartile ranges (IQR))

\begin{tabular}{|c|c|c|c|c|c|c|c|c|c|c|c|}
\hline & \multicolumn{4}{|c|}{ Control (n 723) } & \multicolumn{4}{|c|}{ Intervention ( $n$ 721) } & \multicolumn{3}{|c|}{ Intervention/control } \\
\hline & Mean & $\mathrm{SD}$ & Median & IQR & Mean & SD & Median & IQR & Median & IQR & $P^{\star}$ \\
\hline \multicolumn{12}{|c|}{$\begin{array}{l}\text { Whole-blood concentration } \\
n-3(\mu \mathrm{g} / 100 \mu \mathrm{l}) \dagger\end{array}$} \\
\hline EPA & $1 \cdot 27$ & 0.60 & $1 \cdot 14$ & $0.88-1.54$ & 1.42 & 0.67 & $1 \cdot 29$ & $0.96-1.68$ & $1 \cdot 11$ & $1 \cdot 07-1 \cdot 15$ & $<0.0001$ \\
\hline $\mathrm{DHA}$ & $6 \cdot 27$ & $1 \cdot 70$ & $6 \cdot 13$ & $5 \cdot 07-7 \cdot 21$ & 6.59 & $1 \cdot 78$ & $6 \cdot 45$ & $5 \cdot 33-7 \cdot 69$ & 1.05 & $1.03-1.07$ & $<0.0001$ \\
\hline $\mathrm{EPA}+\mathrm{DHA}$ & $7 \cdot 54$ & $2 \cdot 16$ & $7 \cdot 30$ & $6 \cdot 01-8 \cdot 73$ & $7 \cdot 99$ & $2 \cdot 35$ & $7 \cdot 77$ & $6 \cdot 28-9 \cdot 33$ & 1.06 & $1.03-1.08$ & $<0.0001$ \\
\hline \multicolumn{12}{|c|}{ Weight percentage (w/w\%) } \\
\hline EPA & 0.6 & 0.3 & 0.5 & $0.4-0.7$ & 0.6 & 0.3 & 0.6 & $0.4-0.8$ & $1 \cdot 1$ & $1 \cdot 1-1 \cdot 2$ & $<0.0001$ \\
\hline $\mathrm{DHA}$ & $2 \cdot 8$ & 0.7 & $2 \cdot 8$ & $2 \cdot 3-3 \cdot 3$ & $3 \cdot 0$ & 0.7 & $3 \cdot 0$ & $2 \cdot 5-3 \cdot 5$ & $1 \cdot 1$ & $1 \cdot 0-1 \cdot 1$ & $<0.0001$ \\
\hline$E P A+D H A$ & 3.4 & 0.9 & $3 \cdot 3$ & $2 \cdot 7-3 \cdot 9$ & $3 \cdot 6$ & $1 \cdot 0$ & $3 \cdot 5$ & $3 \cdot 0-4 \cdot 2$ & $1 \cdot 1$ & $1 \cdot 1-1 \cdot 1$ & $<0.0001$ \\
\hline
\end{tabular}

* The intervention and control periods are compared in a paired $t$ test.

† Limit of quantification ranged between 0.007 and $0.01 \mu \mathrm{g} / 100 \mu \mathrm{l}$ as determined by calibration curves. 
Table 5. Adjusted* and unadjusted Spearman's rank correlations between reported intake of fish and whole-blood EPA + DHA concentrations and weight percentages in the control period with packed lunches and in the intervention period when served a New Nordic Diet for lunch

\begin{tabular}{|c|c|c|c|c|c|c|c|c|}
\hline & \multicolumn{4}{|c|}{ Control } & \multicolumn{4}{|c|}{ Intervention } \\
\hline & \multicolumn{2}{|c|}{ Unadjusted (n 658) } & \multicolumn{2}{|c|}{ Partial ( $n$ 657) } & \multicolumn{2}{|c|}{ Unadjusted ( $n$ 651) } & \multicolumn{2}{|c|}{ Partial ( $n$ 649) } \\
\hline & $r$ & $P$ & $r$ & $P$ & $r$ & $P$ & $r$ & $P$ \\
\hline \multicolumn{9}{|c|}{ Whole-blood concentration EPA+DHA $(\mu \mathrm{g} / 100 \mu \mathrm{l})$} \\
\hline Total fish intake & 0.38 & $<0.0001$ & 0.39 & $<0.0001$ & 0.30 & $<0.0001$ & 0.30 & $<0.0001$ \\
\hline Fatty fish intake & 0.40 & $<0.0001$ & 0.40 & $<0.0001$ & 0.29 & $<0.0001$ & 0.29 & $<0.0001$ \\
\hline Lean fish intake & $0 \cdot 21$ & $<0.0001$ & 0.21 & $<0.0001$ & 0.12 & 0.0020 & $0 \cdot 13$ & 0.0015 \\
\hline \multicolumn{9}{|c|}{ Weight percentage EPA + DHA (w/w\%) } \\
\hline Total fish intake & 0.38 & $<0.0001$ & 0.38 & $<0.0001$ & 0.36 & $<0.0001$ & 0.36 & $<0.0001$ \\
\hline Fatty fish intake & 0.41 & $<0.0001$ & 0.41 & $<0.0001$ & 0.35 & $<0.0001$ & 0.35 & $<0.0001$ \\
\hline Lean fish intake & 0.20 & $<0.0001$ & $0 \cdot 19$ & $<0.0001$ & 0.14 & 0.0003 & $0 \cdot 15$ & 0.0002 \\
\hline
\end{tabular}

${ }^{*}$ Adjusted for sex, grade, household education, BMI and fish oil supplement.

fish intake increased by $10 \mathrm{~g} / \mathrm{d}$, then the EPA + DHA level in whole blood increased by 3 (95\% CI 2, 4)\% in the control period and with very similar results in the intervention period. Using $\mathrm{w} / \mathrm{w} \%$ EPA + DHA gave similar results; however, a significant interaction with study period was found for the relationship between $\mathrm{EPA}+\mathrm{DHA}(\mathrm{w} / \mathrm{w} \%$ but not $\mu \mathrm{g} / 100 \mu \mathrm{l})$ and intake of fatty fish (Table 6)

\section{Discussion}

Comparing the accuracy of reported intake of signature foods with observed intake at school lunch

In American studies, conducted by Baxter ${ }^{(13)}$, in the same age group, less accuracy was found when reporting school meals than in the present study. The studies by Baxter have reported intrusion rates from 16 to $54 \%$ and omission rates from 32 to $67 \%$. In the present study, the intrusion rates for both total foods and signature foods were well below 54\%. It is worth to note that omission rates seem to be a larger problem than intrusion rates in the studies of Baxter et al. ${ }^{(13)}$ In the present study, it is the other way around. This might be explained by

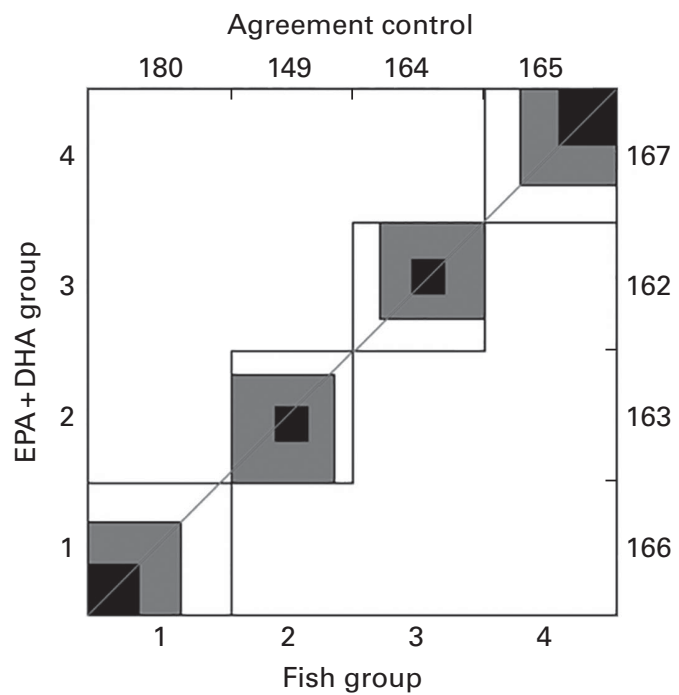

the fact that in the present study, children had parental assistance helping to remember what was in the packed lunch and what was on the menu for the NND lunch meals. Furthermore, in the present study, a consecutive record/recall method was used; in the studies by Baxter ${ }^{(13)}$, a 24-h recall method is used, which could affect memory.

The lower reporting accuracy of signature foods in the present study during the intervention period could probably be caused by the different presentations of foods on the portion size images compared with the actual NND food items served. Parents were also less able to help with the reporting since they did not prepare or see the NND meals. The children may also have reported all the served NND foods and not subtracted waste when judging their portion size ${ }^{(30)}$. The children were encouraged to take everything of the lunch meal on their plate. However, from the photographs, it was obvious that for some foods, they only had a taste, but reported a full portion size. The relative total food waste at lunch and relative waste of potatoes, fish and vegetables was larger during the intervention than during the control period (results not shown), which substantiates to this

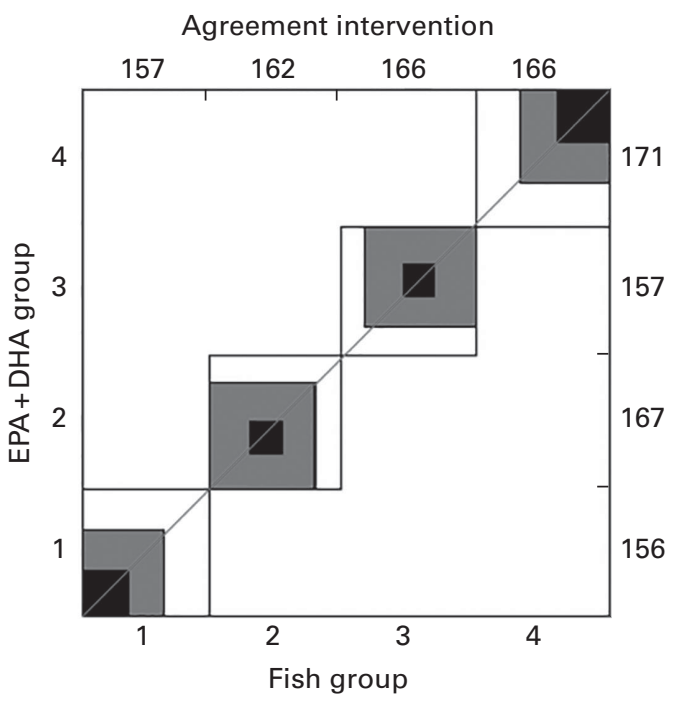

Fig. 1. Agreement of fish intake and EPA + DHA in fasting whole blood $(\mu \mathrm{g} / 100 \mu \mathrm{l})$. The left plot shows the control period and the right the intervention period. The figure illustrates the exact agreement if fish and EPA + DHA place the person in the same group ( $\square)$ and partial agreement if the person is placed in the neighbouring categories $(\square)$. 
Table 6. The association* between whole-blood EPA + DHA concentration and weight percentage and fish intake in the control period with packed lunches and in the intervention period when served a New Nordic Diet (NND) for lunch

(Estimates and $95 \%$ confidence intervals)

\begin{tabular}{|c|c|c|c|c|c|c|c|}
\hline & \multicolumn{3}{|c|}{ Control (n 649) } & \multicolumn{3}{|c|}{ Intervention ( $n$ 657) } & \multirow[b]{2}{*}{ Diet $\times$ order interaction $\dagger$} \\
\hline & Estimate & $95 \% \mathrm{Cl}$ & $P^{\star}$ & Estimate & $95 \% \mathrm{Cl}$ & $P^{\star}$ & \\
\hline \multicolumn{8}{|c|}{ Whole-blood concentration $n-3(\mu \mathrm{g} / 100 \mu \mathrm{l})$} \\
\hline Total fish intake (per $10 \mathrm{~g}$ ) & 1.03 & $1.02,1.04$ & $<0.0001$ & 1.03 & $1.02,1.03$ & $<0.0001$ & 0.2280 \\
\hline Fatty fish intake & 1.05 & $1.03,1.06$ & $<0.0001$ & 1.03 & $1.02,1.04$ & $<0.0001$ & 0.0763 \\
\hline Lean fish intake & 1.02 & $1.01,1.04$ & 0.0031 & 1.01 & $1.00,1.02$ & 0.0255 & 0.2966 \\
\hline \multicolumn{8}{|l|}{ Weight percentage (w/w\%) } \\
\hline Total fish intake (per $10 \mathrm{~g}$ ) & 1.03 & $1.02,1.04$ & $<0.0001$ & 1.03 & $1.02,1.03$ & $<0.0001$ & 0.3877 \\
\hline Fatty fish intake & 1.04 & $1.03,1.05$ & $<0.0001$ & 1.02 & $1.02,1.03$ & $<0.0001$ & 0.0142 \\
\hline Lean fish intake & 1.02 & $1.01,1.03$ & 0.0014 & 1.02 & $1.01,1.03$ & $<0.0001$ & 0.9202 \\
\hline
\end{tabular}

* Linear mixed model adjusted for sex, grade, BMI group, education, fish oil supplement and session and random effects of school, class and child.

† There may be a different NND effect for the different periods depending on if the children were served the NND in the first or second study period, and this was added as an interaction to the model.

interpretation. The foods and textures of the NND may also be unknown for the children, which are reflected in the many zero intakes during the control period. This might have made it more difficult to remember and find the correct food in WebDASC and estimate portion sizes in the intervention period. This may also be reflected in the percentage of reporting faults, which increased significantly during the intervention period. Previous studies have shown that it is more difficult for children to record unfamiliar foods compared with familiar foods ${ }^{(31,32)}$ and to report condiments ${ }^{(2)}$. Furthermore, during the intervention period with the NND school meals, some signature foods were to be incorporated in dishes, e.g. for a soup, the potatoes were served beside the soup, but were intended to be added into the soup by the children and eaten mixed with the soup. Making the soup and the potatoes into one food item can have made it more difficult afterwards to remember that there was actually two food items to be reported.

The NND foods were displayed in the WebDASC browse search in daily menus saving the respondents from searching for each food item. It was intended to minimise reporting errors for foods included in the daily NND lunch menu. Furthermore, the daily menu could be obtained through a link in the WebDASC. However, obviously not all have used the browse search function, and/or taken the time to look at the daily menu before reporting. This could indicate that timely in-person instruction in diet reporting is important for the quality of dietary data. The intervention period was 3-6 months away when the participants received the instructions in the diet reporting.

Overall, the present results show that the diet was more difficult to report accurately during the intervention period compared with the control period. Portion size estimation seemed to be a large problem, and portion sizes were often overestimated compared with the actual portion size for the school lunch foods and especially during the intervention. Since under-reporting seemed to increase during the intervention period and parental intentions to eat healthy were high, it would be reasonable to assume that reporting of less healthy foods such as confectionary and candy would be underestimated. However, this has not been investigated in the present study.
Unlike the present study, an American study by Harrington et $a l .{ }^{(33)}$ has investigated whether reports of fruit and vegetable intake differed between the treatment conditions: control; school intervention; school plus home intervention. The study has found no difference in the reporting accuracy among different conditions. However, in that study, they did not introduce a whole new diet, and the presentation of fruits and vegetables did not differ between conditions.

\section{Comparing reported fish intake with EPA + DHA}

When comparing reported fish intake to EPA + DHA, correlation coefficients and $\kappa$ statistics seemed slightly higher for the control period compared with the intervention period irrespective of using EPA + DHA $\mu \mathrm{g} / \mu \mathrm{l}$ or $\mathrm{w} / \mathrm{w} \%$ as reference. However, the linear mixed models showed positive associations of the same magnitude in the control and intervention periods. The significant increase in whole-blood EPA and DHA (LB Sørensen, CT Damsgaard, SM Dalskov, RA Petersen, N Egelund, CB Dyssegaard, KD Stark, A Andersen, I Tetens, A Astrup, KF Michaelsen and L Lauritzen, unpublished results) and the observations confirm that the intake of fish and other signature foods did increase during the intervention period. The results revealed that the most frequent reporting error was intrusion and reporting too large of a portion size, and that this error was larger during the intervention period than in the control period. This implies that the real increase in the intake of signature foods probably was slightly smaller than that reported. This can be interpreted as an effect of the unblinded intervention.

This is the only validation study to use fasting whole blood as a biomarker for children's reports of fish intake during the control and intervention conditions.

Recent validation studies conducted with adults used food records, 24-h dietary recalls or FFQ with EPA and/or DHA in subcutaneous fat or blood component concentrations as reference methods and reported correlation coefficients in the range of $0 \cdot 19-0 \cdot 60^{(15,16,19)}$. In the present study conducted with children, the correlation between the total reported fish intake and whole-blood EPA + DHA was in agreement with the studies mentioned above, and may be considered as an 
acceptable result as the present study was conducted with children and included the reporting of completely new and unknown foods in lunch meals. No other studies have also delivered quartile agreement between estimated fish intake and EPA and/or DHA biomarker. However, a few have performed quartile agreement between estimated EPA and/or DHA intake and blood biomarker EPA and DHA and found that $77-83 \%$ was classified in the same or adjacent quartile ${ }^{(15,34)}$. The quartile agreement in the present study is also in line with these previous studies. Using either $\mu \mathrm{g} / \mu \mathrm{l}$ or $\mathrm{w} / \mathrm{w} \%$ gave similar results. It has previously been suggested that using fatty acid results expressed as concentrations and those calculated on a weight percentage basis may lead to different results ${ }^{(21)}$. In the weight percentage calculations, each fatty acid has an effect on the composition of the other fatty acids, an interdependence that requires an understanding of fatty acid metabolism, exogenous factors and the contribution of various body pools ${ }^{(35)}$. Using concentration-based results can be more readily interpreted ${ }^{(21,36)}$. A significant interaction with study period was found for the association between $\mathrm{EPA}+\mathrm{DHA} \mathrm{w} / \mathrm{w} \%$ and the intake of fatty fish, which was not found for EPA + DHA $\mu \mathrm{g} / 100 \mu \mathrm{L}$. Since the children were served the same fatty fish (baked salmon) at the same frequency during the study periods, the results could imply that $\mathrm{EPA}+\mathrm{DHA} \mathrm{w} / \mathrm{w} \%$ might be more sensitive to other changes in the diet.

\section{Strengths and limitations}

In the present study, we had a relatively large sample of children and reference information was obtained from two objective methods, which were not likely to have correlated errors with the dietary assessment method. In the present cross-over study, each cross-over participant served as his or her own control. This reduces the influence of confounding such as genetic and metabolic characteristics of the population ${ }^{(35)}$. The photographic observation provided detailed information about reporting errors of specific foods and also captured portion size estimation. Having the intake on photographs and the weight of the meal gave the opportunity to capture details, e.g. condiments, and time to evaluate the reported portion sizes by comparing them with food images and known weight of these. This method is also less sensitive to observer variability than methods using different dieticians to observe intake, because the same dietitian is able to score all images.

Limitations of the present approach were that the children had their packed lunches with them all morning, and some children may have eaten food items before lunch time, but still have recorded these items as lunch. Therefore, food items could have appeared as recorded in the WebDASC, but not on the images and thereby contributed to a higher intrusion rate. The photographing and weighing of the children's plates can have affected the intake or reporting. However, the children were not aware of the exact purpose of the photographing and weighing, but the parents might have helped the children reporting larger portion sizes of the healthier foods, since they were aware of being observed.

\section{Conclusions}

Overall, the results showed that the reporting of all foods were more accurate compared with the reporting of signature foods, and that the accuracy was higher during the control period compared with the intervention period. Most reporting errors were due to selecting a portion size adjacent to actual portion size. This could be due to the unusual NND meals compared with familiar packed lunches, and that it was difficult to estimate the portion sizes of the unusual presentations of foods and that parents were less able to help. Although moderately representing 'true' intake, self-reported intakes of the NND signature foods appear to represent a true increase in intake and is suitable for examining the efficacy of the OPUS intervention.

Improving dietary reporting in future school meal intervention studies that introduce a whole new meal concept in the diet reporting may include a filtering question regarding the intake of intervention meals followed by a search facility where only the food items of the new diet are accessible and arranged in daily menus. Finally, developing illustrative/ representative portion size aids for the intervention diet seems to be important.

\section{Acknowledgements}

The authors thank all the children and their parents/guardians for their participation in the study; research data manager Karsten Kørup, National Food Institute, Technical University of Denmark for facilitating a clear and easy scoring procedure on the Web, helping processing the data, and making the dietary intake calculations; students and trainees from Metropol University College, Copenhagen, the University of Copenhagen and several colleagues from the Division of Nutrition, National Food Institute, Technical University of Denmark and Department of Nutrition, Exercise and Sports, University of Copenhagen for their help collecting the observational data and blood samples; Dr Tom Baranowski and his group at Children's Nutrition Research Center at Baylor College of Medicine, Houston, for letting us use their extensive and carefully developed portion size image series.

The present study was supported by a grant from the Nordea Foundation (grant no. 02-2010-0389). The funder had no role in the design and analysis of the study or in the writing of the article.

None of the authors has any conflict of interest to declare.

The authors' contributions are as follows: A. B.-J., C. T. D., I. T., L. B. S. and A.-V. T. designed the study; A. B.-J. and A.-V. T. formulated the research questions; A.-V. T. collected the observational data; R. A. and M. E. collected the dietary intake data; K. D. S. undertook the whole-blood fatty acid analysis; E. W. A. undertook the statistical analyses in cooperation with A. B.-J.; K. H. Y. designed the recipe database and quality checked the observational data; T. C. undertook the calculations of the dietary intake data; A. B.-J. drafted the manuscript. All authors took part in a critical revision of the manuscript and approved the final content. 


\section{References}

1. Hedrick VE, Dietrich AM, Estabrooks PA, et al. (2012) Dietary biomarkers: advances, limitations and future directions. Nutr J 11, 109.

2. Baxter SD, Thompson WO, Davis HC, et al. (1997) Impact of gender, ethnicity, meal component, and time interval between eating and reporting on accuracy of fourth-graders' self-reports of school lunch. J Am Diet Assoc 97, 1293-1298.

3. National Cancer Institute (2007) National Children's Study Dietary Assessment Literature Review. Bethesda, MD: National Cancer Institute. http://appliedresearch.cancer. gov/archive/\#children-ncs_chapter5 (accessed June 2015).

4. Damsgaard CT, Dalskov SM, Petersen RA, et al. (2012) Design of the OPUS School Meal Study: a randomised controlled trial assessing the impact of serving school meals based on the New Nordic Diet. Scand J Public Health 40, 693-703.

5. Mithril C, Dragsted LO, Meyer C, et al. (2012) Guidelines for the New Nordic Diet. Public Health Nutr 15, 1941-1947.

6. Mithril C, Dragsted LO, Meyer C, et al. (2013) Dietary composition and nutrient content of the New Nordic Diet. Public Health Nutr 16, 777-785.

7. Meyer C, Mithril C \& Blauert E (2010) Grundlag for Ny Nordisk Hverdagsmad (The Foundation for and Definition of a New Nordic Diet). Copenhagen: Københavns Universitet, Institut for Human Ernæring.

8. Biltoft-Jensen A, Trolle E, Christensen T, et al. (2014) WebDASC: a web-based dietary assessment software for 8-11-year-old Danish children. J Hum Nutr Diet 27, Suppl. 1, 43-53.

9. Biltoft-Jensen A, Hjorth MF, Trolle E, et al. (2013) Comparison of estimated energy intake using Web-based Dietary Assessment Software with accelerometer-determined energy expenditure in children. Food Nutr Res 57 (epublication 17 December 2013).

10. Biltoft-Jensen A, Bysted A, Trolle E, et al. (2013) Evaluation of Web-based Dietary Assessment Software for Children: comparing reported fruit, juice and vegetable intakes with plasma carotenoid concentration and school lunch observations. Br J Nutr 110, 186-195.

11. Sherwood N (2008) Diet assessment in children and adolescents. In Handbook of Childhood and Adolescent Obesity, pp. 73-89 [J Elissa and RG Steele, editors]. New York: Springer.

12. Baglio ML, Baxter SD, Guinn CH, et al. (2004) Assessment of interobserver reliability in nutrition studies that use direct observation of school meals. J Am Diet Assoc 104, $1385-1392$.

13. Baxter SD (2009) Cognitive processes in children's dietary recalls: insight from methodological studies. Eur J Clin Nutr 63, Suppl. 1, S19-S32.

14. Andersen R, Biltoft-Jensen A, Christensen T, et al. (2014) Dietary effects of introducing school meals based on the New Nordic Diet - a randomised controlled trial in Danish children. The OPUS School Meal Study. Br J Nutr 111, 1967-1976.

15. Patterson AC, Hogg RC, Kishi DM, et al. (2012) Biomarker and dietary validation of a Canadian food frequency questionnaire to measure eicosapentaenoic and docosahexaenoic acid intakes from whole food, functional food, and nutraceutical sources. J Acad Nutr Diet 112, 1005-1014.

16. Crispim SP, Geelen A, Souverein OW, et al. (2011) Biomarkerbased evaluation of two 24-h recalls for comparing usual fish, fruit and vegetable intakes across European centers in the EFCOVAL Study. Eur J Clin Nutr 65, Suppl. 1, S38-S47.

17. Dahl L, Maeland CA \& Bjorkkjaer T (2011) A short food frequency questionnaire to assess intake of seafood and n-3 supplements: validation with biomarkers. Nutr J 10, 127.
18. Overby NC, Serra-Majem L \& Andersen LF (2009) Dietary assessment methods on $n-3$ fatty acid intake: a systematic review. Br J Nutr 102, Suppl. 1, S56-S63.

19. Serra-Majem L, Nissensohn M, Overby NC, et al. (2012) Dietary methods and biomarkers of omega 3 fatty acids: a systematic review. BrJ Nutr 107, Suppl. 2, S64-S76.

20. Patterson AC, Metherel AH, Hanning RM, et al. (2014) The percentage of DHA in erythrocytes can detect nonadherence to advice to increase EPA and DHA intakes. Br J Nutr 111, 270-278.

21. Schwertner HA \& Mosser EL (1993) Comparison of lipid fatty acids on a concentration basis vs weight percentage basis in patients with and without coronary artery disease or diabetes. Clin Chem 39, 659-663.

22. Vioque J, Navarrete-Munoz EM, Gimenez D, et al. (2011) Validation of a food frequency questionnaire to assess diet in children aged 4-5 years. J Epidemiol Community Health 65, A199-A200.

23. Parrish LA, Marshall JA, Krebs NF, et al. (2003) Validation of a food frequency questionnaire in preschool children. Epidemiology 14, 213-217.

24. Hoppe C, Biltoft-Jensen A, Trolle E, et al. (2012) Beskrivelse af 8-10 årige og 12-14 årige børns kost - med fokus på indtag $i$ skole og fritidsordning (8-10-Year-Olds and 12-14-Year-Olds Diet Intake with Focus on Intake During School and After School Activities). Copenhagen: DTU Fødevareinstituttet.

25. Henry CJ (2005) Basal metabolic rate studies in humans: measurement and development of new equations. Public Health Nutr 8, 1133-1152.

26. Black AE (2000) The sensitivity and specificity of the Goldberg cut-off for EI:BMR for identifying diet reports of poor validity. Eur J Clin Nutr 54, 395-404.

27. Cole TJ, Bellizzi MC, Flegal KM, et al. (2000) Establishing a standard definition for child overweight and obesity worldwide: international survey. BMJ 320, 1240-1243.

28. Damsgaard CT, Stark KD, Hjorth MF, et al. (2013) n-3 PUFA status in school children is associated with beneficial lipid profile, reduced physical activity and increased blood pressure in boys. Br J Nutr 110, 1304-1312.

29. Armstrong JM, Metherel AH \& Stark KD (2008) Direct microwave transesterification of fingertip prick blood samples for fatty acid determinations. Lipids 43, 187-196.

30. Foster E, Adamson AJ, Anderson AS, et al. (2009) Estimation of portion size in children's dietary assessment: lessons learnt. Eur J Clin Nutr 63, S45-S49.

31. Livingstone MB \& Robson PJ (2000) Measurement of dietary intake in children. Proc Nutr Soc 59, 279-293.

32. Warren JM, Henry CJ, Livingstone MB, et al. (2003) How well do children aged 5-7 years recall food eaten at school lunch? Public Health Nutr 6, 41-47.

33. Harrington KF, Kohler CL, McClure LA, et al. (2009) Fourth graders' reports of fruit and vegetable intake at school lunch: does treatment assignment affect accuracy? J Am Diet Assoc 109, 36-44.

34. Sublette ME, Segal-Isaacson CJ, Cooper TB, et al. (2011) Validation of a food frequency questionnaire to assess intake of $n-3$ polyunsaturated fatty acids in subjects with and without major depressive disorder. J Am Diet Assoc 111, 117-123.

35. Silva V, Barazzoni R \& Singer P (2014) Biomarkers of fish oil omega-3 polyunsaturated fatty acids intake in humans. Nutr Clin Pract 29, 63-72.

36. Kuriki K, Nagaya T, Tokudome Y, et al. (2003) Plasma concentrations of (n-3) highly unsaturated fatty acids are good biomarkers of relative dietary fatty acid intakes: a cross-sectional study. J Nutr 133, 3643-3650. 